\section{Persistent Elevation of Vascular Endothelial Growth Factor and Prostacyclin Following Car- diopulmonary Maladaptation to High Altitude: A Pilot Study}

Le Vy-Van, Michel White, Rhian Touyz, Heather Ross, Yves Tessier, Martin G. Sirois, Montreal Heart Institute and Université de Montréal, Montréal, Quebec, Canada

Background: Exposure to hypobaric hypoxemia causes acute mountain sickness (AMS) in $40 \%$ of subjects acutely exposed to an altitude of $4,000 \mathrm{~m}$. Vascular endothelial growth factor (VEGF) and cytokines appear to play a role in AMS in model systems. The objective of this pilot study was to explore the change in VEGF, the vasodilatory prostacyclin PGI-2, interleukin-6 and thiobarbituric acid reactive substances (TBARS) levels following prolonged exposure to hypobaric hypoxemia on Bolivian Altiplano. The secondary objective was to investigate the relationship between these markers with good versus poor adaptation to high altitude.

Methods: The study population consisted of 7 climbers aged 24-64 yr. One cardiac transplant and one kidney transplant recipients participated in this study. Aerobic capacity was assessed on a treadmill using a RAMP protocol with gas exchange analyses. Blood samples were harvested within $48 \mathrm{hr}$ of departure and within $24 \mathrm{hr}$ returning to sea level.

Results: Selected biochemisty parameters are presented in the table:

\begin{tabular}{|c|c|c|c|c|c|c|}
\hline & \multicolumn{2}{|c|}{ VEGF $(\mathrm{pg} / \mathrm{mL})$} & \multicolumn{2}{c|}{ PGI-2 (pg/mL) } & \multicolumn{2}{c|}{ Il-6 (pg/ mL) } \\
\cline { 2 - 7 } & Pre & Post & Pre & Post & Pre & Post \\
\hline $\begin{array}{c}\text { No-AMS* } \\
(\mathrm{n}=5)\end{array}$ & $\begin{array}{c}232 \\
\pm 54\end{array}$ & $\begin{array}{c}251 \\
\pm 81\end{array}$ & $\begin{array}{c}48.7 \\
\pm 39.2\end{array}$ & $\begin{array}{c}77.6 \\
\pm 60.9\end{array}$ & $\begin{array}{c}14.9 \\
\pm 11.7\end{array}$ & $\begin{array}{c}14.8 \\
\pm 14.1\end{array}$ \\
\hline $\begin{array}{c}\text { AMS-brain } \\
(\mathrm{n}=1)\end{array}$ & 259 & 244 & 85.4 & 62.0 & 40.3 & 51.9 \\
\hline $\begin{array}{c}\text { AMS-CP } \\
(\mathrm{n}=1)\end{array}$ & 222 & 553 & 118 & 311 & 11.3 & 13.7 \\
\hline
\end{tabular}

Data are mean $\pm \mathrm{SD}$. $\mathrm{CP}=$ cardiopulmonary. Both cardiac and Tx recipients did not experience AMS. Maximum altitude achieved: $* 6120-6522$; $† 5680$; $\$ 5300$ meters.
Conclusions: Pulmonary maladaptation to high altitude results in a 2-fold elevated VEGF and PGI-2 without concomitant increase of markers of inflammation or oxidative stress. VEGF does not appear to increase in cerebral maladaptation to high altitude. Further investigations are needed to better understand the role of VEGF and other biomarkers during the process of adaptation or maladaptation to high altitude.

\section{Sexuality and Chronic Respiratory Disease}

Ludwig M, Poulain M, Clinique du Souffle La Solane Osséja, France

Fernandes N, Clinique du Souffle La Vallonie Lodève France

Cals C, Brun A, Cotxet A, Abbate C, André L, Desnot

$P$, Desplan J, Clinique du Souffle La Solane Osséja, France

Ninot $G$, Laboratoire EA "Conduites addictives de

Performance et Santé”, Faculté Sciences et du

Sport, Montpellier, France

Background: At the admission in rehabilitation program, some patients with chronic respiratory disease were asked by a health professional to to answer a questionnaire about their sexuality. The objectives of the study were 1) to determine if sexual problems occurred in patients with respiratory chronic disease ; 2) to assess if these survey problems were linked to respiratory disease; 3 ) to explore the motivation to speak about sexuality during rehabilitation program.

Methods: 52 consecutive respiratory disease subjects $\left(58.3 \pm 9\right.$ yr; $\mathrm{FEV}_{1}=65.5 \pm 21 \%$ predicted, mean \pm SD) answered a sexuality questionnaire survey with rehabilitation team (psychologists, nurses, physiotherapists). This group comprised 26 men and 26 women.

Results: $70 \%$ of patients estimated that respiratory disease had an impact on their sexuality. A visual ana$\log$ scale showed that $62 \%$ of patients were not satisfied. The severity of obstruction $\left(\mathrm{FEV}_{1}\right)$ was not correlated to satisfaction $(\mathrm{r}=.017, P=0.90)$, or frequency $(\mathrm{r}=.08, P=0.55)$. Breathlessness was the most important factor of discomfort in sexual activity (61.5\%). Tiredness and cough came second (32\% and $21 \%$ re- 